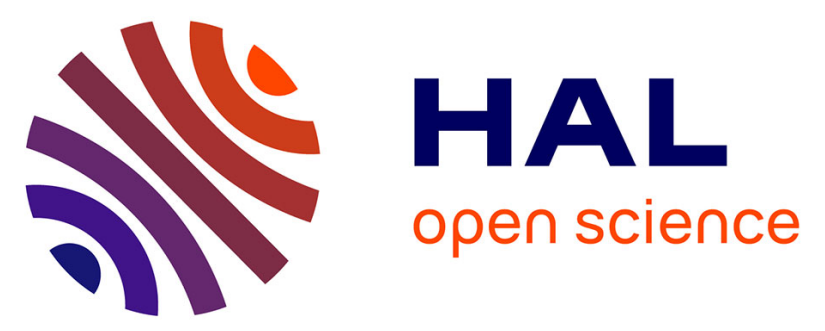

\title{
Fat-free mass at admission predicts 28-day mortality in intensive care unit patients: the international prospective observational study Phase Angle Project
}

R. Thibault, A.-M. Makhlouf, A. Mulliez, M. Cristina Gonzalez, G. Kekstas, N.R. Kozjek, J.-C. Preiser, I.C. Rozalen, S. Dadet, Z. Krznaric, et al.

\section{To cite this version:}

R. Thibault, A.-M. Makhlouf, A. Mulliez, M. Cristina Gonzalez, G. Kekstas, et al.. Fat-free mass at admission predicts 28-day mortality in intensive care unit patients: the international prospective observational study Phase Angle Project. Intensive Care Medicine, 2016, 42 (9), pp.1445-1453. 10.1007/s00134-016-4468-3 . hal-01373305

\section{HAL Id: hal-01373305}

https://hal-univ-rennes1.archives-ouvertes.fr/hal-01373305

Submitted on 4 Nov 2016

HAL is a multi-disciplinary open access archive for the deposit and dissemination of scientific research documents, whether they are published or not. The documents may come from teaching and research institutions in France or abroad, or from public or private research centers.
L'archive ouverte pluridisciplinaire HAL, est destinée au dépôt et à la diffusion de documents scientifiques de niveau recherche, publiés ou non, émanant des établissements d'enseignement et de recherche français ou étrangers, des laboratoires publics ou privés. 


\section{Fat-free mass at admission predicts 28-day mortality in intensive care unit patients: the international prospective observational study PHASE ANGLE PROJECT}

\section{Running title: The PHASE ANGLE PROJECT}

Ronan Thibault, ${ }^{1,2}$ Anne-Marie Makhlouf, ${ }^{1}$ Aurélien Mulliez, ${ }^{3}$ M. Cristina Gonzalez, ${ }^{4}$ Gintautas Kekstas, ${ }^{5}$ Nada Rotovnik Kozjek, ${ }^{6}$ Jean-Charles Preiser, ${ }^{7}$ Isabel Ceniceros Rozalen, ${ }^{8}$ Sylvain Dadet, ${ }^{9}$ Zeljko Krznaric, ${ }^{10}$ Kinga Kupczyk, ${ }^{11}$ Fabienne Tamion, ${ }^{12}$ Noël Cano, ${ }^{13}$ Claude Pichard, ${ }^{1}$ and Phase angle project Investigators

${ }^{1}$ Nutrition unit, Geneva University Hospitals, Geneva, Switzerland

${ }^{2}$ Nutrition unit, Department of Endocrinology, Diabetology and Nutrition, INSERM U991, CHU Rennes, Université Rennes 1, Rennes, France

${ }^{3}$ Department of Biostatistics, Direction of Clinical Research and Innovation, DRCI, CHU Clermont-Ferrand, Clermont-Ferrand, France

${ }^{4}$ University of Pelotas, Pelotas, Brazil

${ }^{5}$ Department of Intensive Care, Vilnius University Hospital, Vilnius, Lithuania ${ }^{6}$ Clinical Nutrition Unit, Institute of Oncology, Ljubljana, Slovenia

${ }^{7}$ Department of Intensive Care, Hôpital Universitaire Erasme, Bruxelles, Belgium

${ }^{8}$ Department of Intensive Care, Clinic USP Palmaplanas, Palma de Majorque, Spain

${ }^{9}$ Department of Nutrition, CHU Clermont-Ferrand, Clermont-Ferrand, France

${ }^{10}$ Departement of Internal Medicine, University Hospital Center Zagreb, Zagreb, Croatia 
${ }^{11}$ Department of Anesthesiology and Intensive Care, University Hospital no $1 \mathrm{CM}$

NCU, Bydgoszcz, Poland

${ }^{12}$ Department of Intensive Care, CHU Rouen, Rouen, France

${ }^{13} \mathrm{CRNH}$, CHU Clermont-Ferrand, Clermont-Ferrand, France

Phase angle project Investigators : Séverine Graf, Claudia P Heidegger (Geneva), Marcio Guerreiro, Silvana Orlandi (Pelotas), Andrius Klimasauskas, Gintare Sostakaite (Vilnius University), Kristina Gorjup, Katja Kogovšek, Katja Kopriva Pirtovšek (Ljubljana), Michelle Norrenberg, Karen Rizkallah, François Wéry (Brussels), Ali Ait Hssain, Bruno Pereira, Bertrand Souweine (Clermont-Ferrand), Steven Grange, Antoine Marchalot, Pauline Bernier-Enguerrand (Rouen), Marlena Jakubczyk, Aleksandra

Różowicz, Stanisław Kłęk (Bydgoszcz, Skawina), Ana Kunovic (Zagreb).

\section{Corresponding author:}

Prof. Ronan Thibault, MD, PhD

Unité de Nutrition

Service d'Endocrinologie-Diabétologie-Nutrition

CHU Rennes

2, rue Henri Le Guilloux

35000 Rennes

France

Phone +33299289646

Fax +33299289647 
E-mail ronan.thibault@chu-rennes.fr

Manuscript word count: 3079 (excluding acknowledgements, funding, conflict of interest disclosures, authors' contributions, references, Tables and Figures legends) 2 Tables -4 Figures.

Abstract word count: 250

Conflict of Interests: research grant from Bioparhom, Le Bourget-du-Lac, France. The authors have no other conflict of interest to declare.

Trial registration: NCT01907347 (http://www.clinicaltrials.gov) 


\section{ABSTRACT}

Purpose: Phase angle measured by bioelectrical impedance analysis reflects fat-free mass. Fat-free mass loss relates to worse prognosis in chronic diseases. Primary aim: to determine the association between fat-free mass at intensive care unit admission and 28day mortality. Methods: Design: multicentre prospective observational study in 10 centres in 9 countries. Inclusion criteria: age $>18$ years, expected length of stay $>48$ hours, absence of pacemaker, heart defibrillator implant, pregnancy or lactation. Fat-free mass was measured by $50 \mathrm{kHz}$ phase angle at admission. Primary endpoint: 28-day mortality. Statistics: Area under the receiver operating characteristic curve (AUC) assessed 28-day mortality prediction by fat-free mass at admission. Multivariable logistic regression: variables associated with 28-day mortality. Results: Out of 3605 screened patients, 931 were analyzed: $61 \pm 16$ years, male $60 \%$, APACHE II $19 \pm 9$, body mass index $26 \pm 6$, day 1 phase angle $4.5 \pm 1.9^{\circ}$. Day 1 phase angle was lower in patients who eventually died than in survivors $\left(4.1 \pm 2.0\right.$ vs $\left.4.6 \pm 1.8^{\circ}, \mathrm{P}=0.001\right)$. Day 1 phase angle AUC for 28-day mortality: 0.63 [0.58-0.67]. In multivariable analysis, were independently associated with 28-day mortality: age (adjusted odds ratio (aOR) 1.014 [95\% confidence interval, 1.002-1.027], $\mathrm{P}=0.03)$, day 1 phase angle $(0.86[0.78-0.96], \mathrm{P}=0.008)$, APACHE II (aOR 1.08 [1.06-1.11], P<0.001), surgical patients (aOR 0.51 [0.33-0.79], $\mathrm{P}=0.002$ ), and admission for other diagnosis (aOR 0.39 [0.21-0.72], $\mathrm{P}=0.003$ ). $\mathrm{A}$ multivariable combined score improved 28-day mortality predictability: AUC $=0.79$ [0.75-0.82]. Conclusion: A low fat-free mass at intensive care unit admission is associated with 28-day mortality. A combined score improves mortality predictability. 
Keywords: bioelectrical impedance analysis; severity of illness index; body composition; critical illness; critical care outcomes 


\section{INTRODUCTION}

Intensive care unit (ICU) patients feature a loss of fat-free mass up to $440 \mathrm{~g} / \mathrm{day}$, which is associated with increased morbidity and prolonged recovery [1]. In several clinical conditions, fat-free mass [2] derived from bioelectrical impedance analysis have been associated with worse clinical outcome [3-7]. However, solid data to support this association in ICU patients are lacking. Only a single retrospective study of 51 ICU patients with acute respiratory failure correlated loss of active cell mass with mortality [8]. In a pilot study published in an abstract form performed in 55 ICU patients, we observed that phase angle measured at $5 \mathrm{kHz}$ was significantly related to the Sequential Organ Failure Assessment (SOFA) $(r=0.38, \mathrm{P}=0.03)$ [9]. These studies suggest that phase angle, that reflects fat-free mass, may be useful in predicting ICU morbidity and mortality (Figure 1).

Bioelectrical impedance analysis is a well validated, non-invasive and relatively inexpensive technique to measure body composition [1]. In the ICU, bioelectrical impedance analysis is frequently described as a non-reliable technique to assess nutritional status through body composition, i.e. fat-free mass or fat mass, because of rapid fluid shifts. This is related to the equations used that have all been validated in clinical situations associated with fluid homeostasis and constant water content. Phase angle is easily, quickly, and repeatedly measured at bedside by bioelectrical impedance analysis. Phase angle is reflecting intracellular status and fat-free mass (Figure 1): altered intracellular water to extracellular water distribution is suggested by low phase angle [3]. 
Phase angle measurement does not require recalled parameters, body weight, and lab tests.

Classic ICU validated severity scores (e.g. Acute Physiology and Chronic Health Evaluation (APACHE), Simplified Acute Physiology Score (SAPS), SOFA) and recent nutritional scores have been developed to foresee the clinical outcome of ICU patients [10]. Most of these scores are time consuming and suffer some degree of discriminative power (i.e. APACHE II and SAPS II are not validated in cardiovascular surgery patients $[11,12])$.

We conducted an international multicentre prospective observational study in ICU patients to assess the prognosis value of fat-free mass at admission (day 1) measured by bioelectrical impedance analysis-derived phase angle. The primary aim was to determine the association between day 1 phase angle and 28-day mortality. The secondary aim was to determine the relation between day 1 phase angle and disease severity scores (APACHE II and SAPS II). 


\section{METHODS}

\section{Study design}

The Phase angle Project is an international multicentre prospective observational study involving the intensive care departments and nutrition units of ten centres in nine countries: Geneva (Switzerland), Pelotas (Brazil), Brussels (Belgium), Vilnius (Lithuania), Clermont-Ferrand (France), Ljubljana (Slovenia), Palma de Majorque (Spain), Bydgoszcz (Poland), Zagreb (Croatia), and Rouen (France). The project was coordinated by the Nutrition unit, Geneva University Hospital, Geneva, Switzerland, with RT as the international study coordinator. The research protocol was approved by the Geneva University Hospitals Ethics Committee, then by the Ethical Committee of each participating hospital. The total number of beds among the participatings ICUs was 320, including $70 \%$ of medical and $30 \%$ of surgical beds.

\section{Patients' recruitment}

Each participating centre had to include 100 consecutive patients. This means that during the inclusion period, each centre should include all admitted patients meeting the inclusion criteria until the goal of 100 included patients was reached. For one single patient, the study duration was one month. The overall inclusion period took place from September $1^{\text {st }} 2012$ and April 30, 2015. The inclusion criteria were: age $>18$ years, expected length of stay $>48$ hours, absence of pacemaker or heart defibrillator implant, absence of known pregnancy or lactation, affiliation to an health insurance, and written informed consent by the patient or her/his next of kin in case of inability to 
consent. Patients were not eligible if they were readmitted 48 hours after their discharge to avoid that a single patient was included twice.

\section{Study endpoints}

The primary endpoint was 28 -day mortality, i.e. mortality during the 28 consecutive days following ICU admission. If patients were discharged from the hospital or transferred in another health care centres, the information of 28-day mortality was collected by examination of medical records, phone call to the hospital department or to the patient's general physician.

The secondary endpoints were APACHE II and SAPS II collected at day 1. Day 1 was defined as the day of ICU admission if patients were admitted at or before noon, or as the day following ICU admission if patients were admitted after noon.

\section{Phase angle measurement by bioelectrical impedance analysis}

$50 \mathrm{kHz}$ phase angle was measured by bioelectrical impedance analysis in every patient at day 1 (day 1 phase angle), and repeated at day 5 for patients still hospitalized in the ICU. After skin cleaning with 70\% ethanol, four adhesive electrodes (3M Red Dot T, 3M Health Care, Borken, Germany) were placed on the dorsal side of the left hand, left wrist, left foot, and left ankle (Figure 1) while the patient was lying supine with hand palms facing inwards. If the left side was not accessible (e.g. wounds, fracture,...), the right side was chosen. Phase angle measurement at day 5 was performed with respect to day 1 electrodes position. An electrical current of $0.8 \mathrm{mAmp}$ was produced at $50 \mathrm{KHz}$ by a generator/analyser (Nutriguard M, DataInput, Gmbh, Darmstadt, Germany) during 
approximately two minutes to measure whole-body resistance $(\mathrm{R})$ and reactance $(\mathrm{Xc})$ [1]. Phase angle was calculated according to the following equation: phase angle (degree) $=$ $\arctan (\mathrm{Xc} / \mathrm{R}) *(180 / \pi)$ (Figure 1).

\section{Data collection}

Weight and height were measured or obtained by the patient ${ }^{\text {s }}$ or their next of kin's interview the day of phase angle measurement by bioelectrical impedance analysis. Body mass index was calculated as weight $(\mathrm{kg})$ divided by squared height $\left(\mathrm{m}^{2}\right)$. Clinical information (primary and secondary admission diagnoses, ICU severity scores, outcomes) was retrieved by each investigator from the hospital electronic medical record. In Geneva University Hospitals, the ICU dedicated computerised information data management system (CliniSoft 6.2, General Electric) was used.

\section{Statistics}

\section{Sample size calculation}

The sample size calculation was based on the main endpoint, the 28-day mortality, the recruitment capacity of each centre and the estimation of statistical power. Based on other recent prospective randomized controlled trials [13,14], and statistics from the ICU department of the Geneva University Hospitals, we expected a 28-day mortality of $15 \%$. To obtain a area under the receiver operating characteristic (ROC) curve assessing 28-day mortality prediction by phase angle of 0.85 , and given bilateral $\alpha$ and $\beta$ risks of 5 and 
$10 \%$, respectively, 1000 patients had to be recruited [15]. We therefore planned to include 100 patients per centre.

\section{Statistical analysis}

Descriptive statistics are expressed as mean \pm standard deviation or median and interquartile range for continuous data, according to their distribution, and number of patients (percent, $\%$, followed immediately after by the counts for the numerator/denominator) for categorical data. Receiver Operating Characteristic curves were used to analyse the association of each variable with 28-day mortality, and to find the best cut-off associated with 28-day mortality according to the Youden method. Receiver Operating Characteristic curves are analysed with their area under the curve (AUC) and its 95\% confidence interval. Discriminative power of AUC was determined according to the following classification: $0.90 \leq \mathrm{AUC} \leq 1.0$, excellent; $0.80 \leq \mathrm{AUC}<0.90$, good; $0.70 \leq \mathrm{AUC}<0.80$, fair; $0.60 \leq \mathrm{AUC}<0.70$, poor; $0.50 \leq \mathrm{AUC}<0.60$, fail [16]. We analyzed 28-day mortality with the $\chi 2$ tests (or Fisher's exact test when appropriate) for categorical data, and the Student's $t$ test (or Mann-Whitney-Wilcoxon test when appropriate) for continuous data. A multivariable logistic regression adjusted for the factors with a P-value $<0.2$ in the univariate analysis was performed with a backward stepwise elimination process eliminating all variables that did not contribute (Pvalue $\geq 0.05$ ). For continuous variables, the adjusted odd ratio was expressed for 1-point increase. From this model we computed a risk-score of 28-day mortality. Results are expressed as adjusted odds ratio and their $95 \%$ confidence interval. The risk-score was used in a Receiver Operating Characteristic curves analysis to assess its discriminative 
power towards 28-day mortality. Sensitivity, specificity, positive predictive value and negative predictive value, and their $95 \%$ confidence interval were calculated according to the Youden method. Statistics were computed with STATA V12 (Stata Corp, College Station, Texas, USA) and two-sided P-value $<0.05$ was considered statistically significant. 


\section{RESULTS}

\section{Patients' selection, characteristics and outcomes}

Among 3605 screened patients, 1009 patients were first included according to the inclusion criteria, and after secondary exclusions (8\%, 77/1009), 931/3605 patients were analyzed (26\% of screened patients) (Figure 2). Sixty-four percent (49/77) of secondary exclusions occurred mainly because bioelectrical impedance analysis was not performed at admission. Analyzed patients were included from the 10 participating centres as follow: Geneva $(n=170)$, Ljubljana $(n=107)$, Pelotas $(n=103)$, Brussels $(n=100)$, Vilnius $(n=100)$, Clermont-Ferrand $(n=99)$, Palma de Majorque $(n=96)$, Rouen $(n=56)$, Bydgoszcz $(n=51)$, and Zagreb $(n=49)$. Patients' characteristics and diagnoses at admission are detailed in Table 1. Mean day 1 phase angle was $4.5 \pm 1.85^{\circ}$ (range: 1.24 21.0). Day 1 phase angle was measured in 932 patients; one patient was secondly excluded because of aberrant result (day 1 phase angle $=0$ ). As expected, day 1 phase angle was lower in older patients, female and patients with lower body mass index (data not shown). SAPS II was collected in 657 patients since it was not collected in routine clinical practice in two centres. Patients' clinical outcomes during follow up are shown in Table 1.

\section{Relation between day 1 fat-free mass and 28-day mortality}

28-day mortality was $19.3 \%(180 / 931)$ (range $9.6-38.8 \%)$, close to the $15 \%$ mortality predicted for the sample size calculation. Day 1 phase angle was lower in non-survivors than in survivors (Table 1 and Figure 3A). This difference failed to reach statistical 
significance at day 5 in the 527/931 patients (57\%) remaining hospitalized in the ICU. The area under the receiver operating characteristic curve assessing 28-day mortality prediction by day 1 phase angle was: 0.63 [95\% confidence interval, 0.58-0.67] (Figure 3B), indicating a poor discriminative power of day 1 phase angle. 28 -day mortality was higher in patients with day 1 phase angle $<3.49(31 \%, 86 / 275)$ than with Day 1 phase angle $\geq 3.49(14 \%, 94 / 656), \mathrm{P}<0.001$. The areas under the Receiver Operating Characteristic curve assessing 28-day mortality prediction by APACHE II $(\mathrm{n}=901)$ or SAPS II ( $\mathrm{n}=657)$ indicated also a poor / fair discriminative power of APACHE II and SAPS II: 0.69 [95\% confidence interval, $0.65-0.73]$ and 0.72 [95\% confidence interval, 0.67-0.77], respectively. Univariate analysis of factors associated with 28-day mortality is shown in Table 1. For the multivariable analysis (Table 2), APACHE II and body mass index were missing in 30 and six patients, respectively, representing 3.9\% (36/931), of missing data. As indicated in Table 2, variables significantly associated with increased 28-day mortality in multivariable logistic regression were: day 1 phase angle, APACHE II, surgical admission diagnosis, admission for another diagnosis that one of those listed, and age. A multivariable composite risk-score improved 28-day mortality predictability. The score was determined by multivariable logistic regression and calculated as: riskscore $=-3.55[95 \%$ confidence interval, $-4.67 ;-2.43]-0.67[-1.11 ;-0.24]$ (if surgical admission diagnosis $)+0.014[0.002 ; 0.027]^{*}$ age $-0.146[-0.254 ;-0.039] *$ Day 1 phase angle $+0.0784 *$ APACHE II $-0.94[0.054 ; 0.102]$ (if admission diagnosis is another one of those listed)]. For a score $\geq 0.1716$, sensitivity, specificity, positive predictive value, and negative predictive value, were 77\%, 132/172, [95\% confidence interval, $70-$ 83]; 66\%, 477/723, [62-69]; 35\%, 132/378, [30-40]; and 92\%, 477/517, [90-94], 
respectively. The area under the Receiver Operating Characteristic curve of this riskscore was: 0.79 [95\% confidence interval, $0.75-0.82]$ (Figure 4), improving the discriminative power either values of day 1 phase angle, or APACHE II or SAPS II alone.

\section{Relation between day 1 phase angle and ICU severity scores}

There was a correlation between day 1 fat-free mass and ICU severity scores. APACHE II and SAPS II were significantly higher in patients with day 1 phase angle $<3.49$ than in patients with day 1 phase angle $\geq 3.49$ (APACHE II, $21.8 \pm 9.2$ vs. $17.7 \pm 8.7, \mathrm{P}<0.001$; SAPS II, $48.0 \pm 19.2$ vs. $40.5 \pm 18.3, \mathrm{P}<0.001)$. 


\section{DISCUSSION}

In this international multicentre prospective observational study, a low fat-free mass measured by bioelectrical impedance analysis-derived phase angle at ICU admission was associated with increased 28-day mortality. A multivariable combined score (including day 1 phase angle, APACHE II, and other parameters) improves the discriminative power of 28-day mortality compared to either values of day 1 phase angle, or APACHE II or SAPS II alone. This study suggests that phase angle could be used as part of prognosis markers at ICU admission.

In the non-ICU patients, bioelectrical impedance analysis is a well validated and easy-touse method to measure at bedside body composition: fat-free mass, fat mass, and total, intra- and/or extracellular body water, as well as an easy and quick measurement of phase angle that is a reflect of fat-free mass. A low phase angle is reflecting fat-free mass loss and cell dysfunction whereas a higher value ( $>6$ in normal subjects [17]) is reflecting good cell health or nutritional status (Figure 1). Low phase angle has been correlated with a worse disease prognosis in oncology [5, 18-21], human immunodeficiency virus infection [6], amyotrophic lateral sclerosis [22], geriatric [23], renal dialysis in chronic renal failure [24], liver cirrhosis [25], acquired immune deficiency syndrome [26], and gastrointestinal surgical patients [27]. The phase angle cut-off associated with increased mortality is variable: $<2.5^{\circ}$ in amyotrophic lateral sclerosis [22], $<3.5^{\circ}$ in geriatrics [23], from $<1.65$ to $<5.6^{\circ}$ in oncology [18-21], $<5.4^{\circ}$ in cirrhosis [25], and, in our study, $<3.49^{\circ}$ at ICU admission. These differences among cut-offs could be explained by the lack of homogeneity between these different study populations. The relation of fat-free 
mass loss, defined as a low phase angle, with prognosis and illness severity reinforces the interest in using bioelectrical impedance analysis for the clinical management of patients with acute (e.g. ICU) or chronic diseases.

The relationship between fat-free mass and mortality failed to reach statistical significance at day 5. No single explanation is available. This could be related to the reduction of the study sample at day 5 because of early discharge. However, one could have expected a significant relationship between day 5 fat-free mass and mortality. Indeed, at the early phase of ICU stay (i.e. the first 96 hours), critically ill patients feature a loss of fat-free mass up to $440 \mathrm{~g} /$ day, which is associated with increased morbidity and prolonged recovery [1]. One could hypothesize that patients with fat-free mass loss at day 5 should more suffer from functional impairment or ICU-acquired weakness [28-30], or could be at increased risk of late mortality (post-28-day).

In our study, APACHE II or SAPS II has a poor/fair discriminative value to predict 28day mortality. Areas under the receiver operating characteristic curves are much below the values reported in the validation studies of these ICU severity scores $[11,12]$. This could be explained by the lower sample size or by patients' selection: in the APACHE II validation study, were included only cardiac surgery patients [11], in the SAPS II validation study, were excluded patients with coronary care or cardiac surgery [12], whereas our ICU population was mixed with six percent of cardiac patients. Interestingly, in our study, the mortality predictability of either day 1 phase angle, SAPS II or APACHE II alone was much improved by a multivariable model including day 1 phase angle and APACHE II, among other variables. This indicates that phase angle, a marker of fat-free mass, illness severity and cell health improves mortality predictability of ICU 
severity scores. These ICU severity scores are built from clinical and biological data that could not reflect strictly an alteration of cell functions, as does the phase angle.

Moreover, phase angle values are dependent on gender, age, and nutritional status: phase angle is lower in female, older, or patients with loss of fat-free mass, i.e. malnourished [17]. Therefore by combining ICU severity scores with a marker of fat-free mass loss, whatever its aetiology (disease severity, chronic diseases, ageing,...), the prognostic value could be improved.

Phase angle is calculated only from two clinical parameters, reactance and resistance, reflecting the electrical properties of body cells. By this fact, phase angle may be less dependent on fluid variations than usual body composition equations. However one could speculate that, in the ICU, rapid fluid shifts, overhydration or dehydration status could contribute to cell damage and therefore be associated with a decreased phase angle. Further studies are needed to better assess the relation between body mass index, body composition including water compartments, and phase angle, in ICU patients. Another applicability of bioelectrical impedance analysis in the ICU could be the bioelectrical impedance vector analysis (BIVA). Indeed Jones et al showed that repeated BIVA hydration measurements could detect fluid accumulation or fluid balance $>2$ litres in ICU patients [31]. However studies are needed to better define bioelectrical impedance analysis-derived phase angle and BIVA place in the ICU patients' management.

In our study, patients with pacemaker or implantable cardioverter defibrillators were excluded from the study according to the latest European Society for Clinical Nutrition and Metabolism guidelines [2]. However, two studies [32,33] have proven that 
bioelectrical impedance analysis can be safely performed in patients equipped with implantable cardioverter defibrillators.

Study limitations. We planned to analyze 1000 patients on a basis of 100 patients per centre, but, due to secondary exclusions, 931 patients were analyzed, and due to $3.9 \%$ of missing data, multivariable analysis was performed in 895 patients. Phase angle was shown to be predictive of 28-day mortality in ICU population, known to have rapid fluid shifts. The exact role of these fluid shifts on the observed findings remains to be determined. As previously reported [31], bioelectrical impedance analysis could not be systematically performed in the best conditions: in patients who could not be positioned in a full supine position due to clinical constraints (e.g., those with head injury and intracranial pressure monitoring); on occasion the positioning of the electrodes had to be modified slightly because of the presence of other devices (e.g., intravenous cannulas and soft restraints).

In conclusion, fat-free mass loss, measured at ICU admission by bioelectrical impedance analysis-derived phase angle, is associated with 28 -day mortality. Day 1 phase angle, APACHE II, and SAPSII, alone, have a poor discriminative power. A multivariable combined score improves 28-day mortality predictability. Bioelectrical impedance analysis-derived phase angle could be used as a marker of illness severity in the ICU patients. As fat-free mass loss, i.e. low phase angle, defines malnutrition, future studies may be designed to assess whether nutritional interventions targeted to phase angle values could change patients' outcome. 


\section{Acknowledgements}

The authors gratefully thank Gaëlle Emvalomenos and Thora Theodorsdottir for their help to recruit patients at Geneva University Hospital and database management and all the nurse staff and physicians in all the investigating centres. We especially thank Dr Fabrice Kwiatkowski, biostatistician, at Jean Perrin's Cancer Centre, Clermont-Ferrand, France, for his careful review of all statistical analyses.

Funding: The Phase angle Project was supported by the European Society for Clinical Nutrition and Metabolism (ESPEN) as a fellowship grant 2012 allocated to Ronan Thibault. Additional research grants (five percent of the main funding by ESPEN) were obtained from Bioparhom, Le Bourget-du-Lac, France and the public Foundation Nutrition 2000Plus, Switzerland.

Conflict of Interest disclosures: Research grant from Bioparhom, Le Bourget-du-Lac, France.

\section{Authors' contributions}

Ronan Thibault conceived the study, participated in its design, obtained funding, coordinated the study, recruited patients, collected, analyzed and interpreted the data, managed the database, and drafted the manuscript. Anne-Marie Makhlouf recruited patients, collected the data, and managed the database. Aurélien Mulliez performed the statistical analysis. Cristina Gonzalez, Sylvain Dadet, Gintautas Kekstas, Jean-Charles 
Preiser, Nada Rotovnik Kozjek, Isabel Ceniceros Rozalen, Kinga Kupczyk, Zeljko Krznaric, and Fabienne Tamion recruited patients and collected the data. Noël Cano conceived the study and obtained funding. Claude Pichard conceived the study, participated in its design, obtained funding, participated in the interpretation of the data, and drafted the manuscript. 


\section{References}

1. Kyle UG, Bosaeus I, De Lorenzo AD, et al (2004) Bioelectrical impedance analysis-part I: review of principles and methods. Clin Nutr 23:1226-1243

2. Kyle UG, Bosaeus I, De Lorenzo AD, et al (2004) Bioelectrical impedance analysispart II: utilization in clinical practice. Clin Nutr 23:1430-1453

3. Thibault R, Genton L, Pichard C (2012) Body composition: why, when and for who? Clin Nutr 31:435-447

4. Pichard C, Kyle UG, Morabioelectrical impedance analysis A, Perrier A, Vermeulen B, Unger P (2004) Nutritional assessment: lean body mass depletion at hospital admission is associated with an increased length of stay. Am J Clin Nutr 79:613-618 5. Gupta D, Lammersfeld CA, Burrows JL, et al. (2004) Bioelectrical impedance phase angle in clinical practice: implications for prognosis in advanced colorectal cancer. Am J Clin Nutr 80:1634-1638

6. Schwenk A, Beisenherz A, Römer K, Kremer G, Salzberger B, Elia M (2000) Phase angle from bioelectrical impedance analysis remains an independent predictive marker in HIV-infected patients in the era of highly active antiretroviral treatment. Am J Clin Nutr 72:496-501

7. Hill GL (1992) Jonathan E. Rhoads Lecture. Body composition research: implications for the practice of clinical nutrition. JPEN J Parenter Enteral Nutr 16:197-218

8. Faisy C, Rabbat A, Kouchakji B, Laaban JP (2000) Bioelectrical impedance analysis in estimating nutritional status and outcome of patients with chronic obstructive pulmonary disease and acute respiratory failure. Intensive Care Med 26:518-525 
9. Thibault R, Heidegger CP, Methot C, et al. (2009) relationship between bioelectrical phase angle se angle, sofa score and mortality in intensive care unit (ICU) patients. Clin Nutr 4:36

10. Heyland DK, Dhaliwal R, Jiang X, Day AG (2011) Identifying critically ill patients who benefit the most from nutrition therapy: the development and initial validation of a novel risk assessment tool. Crit Care 15:R268

11. Hekmat K, Doerr F, Kroener A, et al (2010) Prediction of mortality in intensive care unit cardiac surgical patients. Eur J Cardiothorac Surg 38:104-109

12. Le Gall JR, Lemeshow S, Saulnier F (1993) A new Simplified Acute Physiology Score (SAPS II) based on a European/North American multicenter study. JAMA 270:2957-2963

13. Heidegger CP, Berger MM, Graf S, et al (2013) Optimization of energy provision with supplemental parenteral nutrition (SPN) in critically ill patients: a randomised controlled clinical trial. Lancet 381: 385-93

14. Doig GS, Simpson F, Sweetman EA, et al (2013). Early parenteral nutrition in critically ill patients with short-term relative contraindications to early enteral nutrition: a randomized controlled trial. JAMA 309:2130-8

15. Hanley JA, McNeil BJ (1982) The meaning and use of the area under a receiver operating characteristic (ROC) curve. Radiology 143:29-36

16. Swets JA (1988) Measuring the accuracy of diagnostic systems. Science 240:1285-93 17. Bosy-Westphase angle 1 A, Danielzik S, Dörhöfer RP, Later W, Wiese S, Müller MJ (2006) Phase angle from bioelectrical impedance analysis: population reference values by age, sex, and body mass index. JPEN J Parenter Enteral Nutr 30:309-316 
18. Gupta D, Lammersfeld CA, Vashi PG, et al (2009) Bioelectrical impedance phase angle in clinical practice: implications for prognosis in stage IIIB and IV non-small cell lung cancer. BMC Cancer 9:37

19. Gupta D, Lammersfeld CA, Burrows JL, et al (2014) Bioelectrical impedance phase angle in clinical practice: implications for prognosis in advanced colorectal cancer. Am J Clin Nutr 80:1634-1638

20. Gupta D, Lis CG, Dahlk SL, Vashi PG, Grutsch JF, Lammersfeld CA (2004)

Bioelectrical impedance phase angle as a prognostic indicator in advanced pancreatic cancer. Br J Nutr 92:957-962

21. Paiva SI, Borges LR, Halpern-Silveira D, Assunçao MC, Barros AJ, Gonzalez MC (2010) Standardized phase angle from bioelectrical impedance analysis as prognostic factor for survival in patients with cancer. Support Care Cancer 19:187-192 22. Desport JC, Marin B, Funalot B, Preux PM, Couratier P (2008) Phase angle is a prognostic factor for survival in amyotrophic lateral sclerosis. Amyotroph Lateral Scler 9:273-278

23. Wirth R, Volkert D, Rösler A, Sieber CC, Bauer JM (2010) Bioelectric impedance phase angle is associated with hospital mortality of geriatric patients. Arch Gerontol Geriatr 51:290-294

24. Mushnick R, Fein PA, Mittman N, Goel N, Chattopadhyay J, Avram MM (2003) Relationship of bioelectrical impedance parameters to nutrition and survival in peritoneal dialysis patients. Kidney Int Suppl 87:S53-56 
25. Selberg O, Selberg D (2002) Norms and correlates of bioimpedance phase angle in healthy human subjects, hospitalized patients, and patients with liver cirrhosis. Eur J Appl Physiol 86:509-516

26. Schwenk A, Beisenherz A, Römer K, Kremer G, Salzberger B, Elia M (2000) Phase angle from bioelectrical impedance analysis remains an independent predictive marker in HIV-infected patients in the era of highly active antiretroviral treatment. Am J Clin Nutr $72: 496-501$

27. Barbosa-Silva MC, Barros AJ (2005) Bioelectric impedance and individual characteristics as prognostic factors for post-operative complications. Clin Nutr 24: 830838

28. Wischmeyer PE, San-Millan I (2015) Winning the war against ICU-acquired weakness: new innovations in nutrition and exercise physiology. Crit Care;16:56 29. Pichard C, Oshima T, Berger MM (2015) Energy deficit is clinically relevant for critically ill patients: yes. Intensive Care Med;41:335

30. Hoffer LJ, Bistrian BR (2015) Energy deficit is clinically relevant for critically ill patients: no. Intensive Care Med;41:339

31. Jones SL, Tanaka A, Eastwood GM, et al (2015) Bioelectrical impedance vector analysis in critically ill patients: a prospective, clinician-blinded investigation. Crit Care 19:290

32. Buch E, Bradfield J, Larson T, Horwich T (2012) Effect of bioimpedance body composition analysis on function of implanted cardiac devices. Pacing Clin Electrophysiol 35:681-684 
33. Meyer P, Makhlouf AM, Mondouagne Engkolo LP, et al (2016) Safety of bioelectrical impedance analysis in patients equipped with implantable cardioverter defibrillators. JPEN J Parenter Enteral Nutr; Feb 22. pii: 0148607116633823 
Table 1 - Patients' characteristics, diagnoses at intensive care unit admission, and univariate analysis of variables associated

2 with 28-day mortality (n=931). Areas under the receiver operating characteristic curve (AUC) are shown for all variables. Mortality

3 were collected at day 28 even after intensive care unit discharge. The other variables were only assessed during the intensive care unit

4 stay.

\begin{tabular}{|c|c|c|c|c|c|c|c|}
\hline & $\begin{array}{l}\text { Missing } \\
\text { (n) }\end{array}$ & $\begin{array}{l}\text { All } \\
n=931\end{array}$ & $\begin{array}{l}\text { AUC } \\
{[95 \% \mathrm{CI}]}\end{array}$ & $\begin{array}{l}\text { Alive at 28- } \\
\text { DAY } \\
n=751\end{array}$ & $\begin{array}{l}\text { Dead at 28- } \\
\text { DAY } \\
n=180\end{array}$ & OR $[95 \% \mathrm{CI}]$ & $P$-value \\
\hline Male / female $-\mathrm{n}(\%)$ & 0 & $\begin{array}{l}561(60) / \\
370(40)\end{array}$ & $\begin{array}{l}0.50 \\
{[0.46-0.54]}\end{array}$ & $\begin{array}{l}453(60) / \\
298(40)\end{array}$ & $\begin{array}{l}108(60) / \\
72(40)\end{array}$ & $0.99[0.71-1.38]$ & 0.94 \\
\hline Age (year) - mean $\pm \mathrm{SD}$ & 0 & $61.2 \pm 16.3$ & $\begin{array}{l}0.60 \\
{[0.55-0.64]}\end{array}$ & $60.2 \pm 16.4$ & $65.5 \pm 15.3$ & $1.02[1.01-1.03]$ & $<0.001$ \\
\hline $\begin{array}{l}\text { Age }<65 / \geq 65 \text { years } \\
-\mathrm{n}(\%)\end{array}$ & 0 & $\begin{array}{l}463(50) / \\
468(50)\end{array}$ & $\begin{array}{l}0.59 \\
{[0.55-0.63]}\end{array}$ & $\begin{array}{l}400(53) / \\
351(47)\end{array}$ & $\begin{array}{l}63(35) / \\
117(65) \\
\end{array}$ & $2.12[1.51-2.97]$ & $<0.001$ \\
\hline 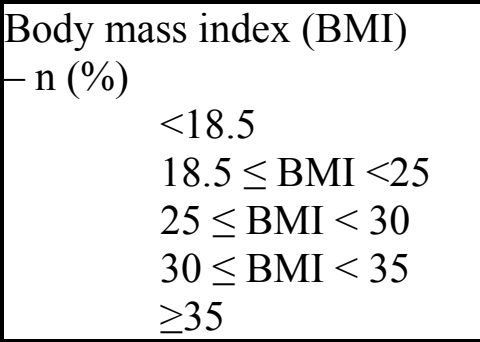 & 6 & $\begin{array}{l}31(3) \\
409(44) \\
274(30) \\
140(15) \\
71(8)\end{array}$ & $\begin{array}{l}0.53 \\
{[0.49-0.57]}\end{array}$ & $\begin{array}{l}22(3) \\
329(44) \\
222(30) \\
113(15) \\
62(8)\end{array}$ & $\begin{array}{l}9(5) \\
80(45) \\
52(29) \\
27(15) \\
9(5)\end{array}$ & $\begin{array}{l}1.66[0.74-3.75] \\
\text { Reference } \\
0.95[0.65-1.40] \\
0.97[0.60-1.58] \\
0.59[0.28-1.24]\end{array}$ & $\begin{array}{l}0.42 \\
0.21 \\
- \\
0.85 \\
0.94 \\
0.17\end{array}$ \\
\hline $\begin{array}{l}\text { Day } 1 \text { phase angle } \\
<3.49 / \geq 3.49-\mathrm{n}(\%)\end{array}$ & 0 & $\begin{array}{l}275(30) / \\
656(70)\end{array}$ & $\begin{array}{l}0.61 \\
{[0.57-0.65]}\end{array}$ & $\begin{array}{l}189(25) / \\
562(75)\end{array}$ & $\begin{array}{l}86(48) / \\
94(52)\end{array}$ & $2.72[1.94-3.81]$ & $<0.001$ \\
\hline
\end{tabular}




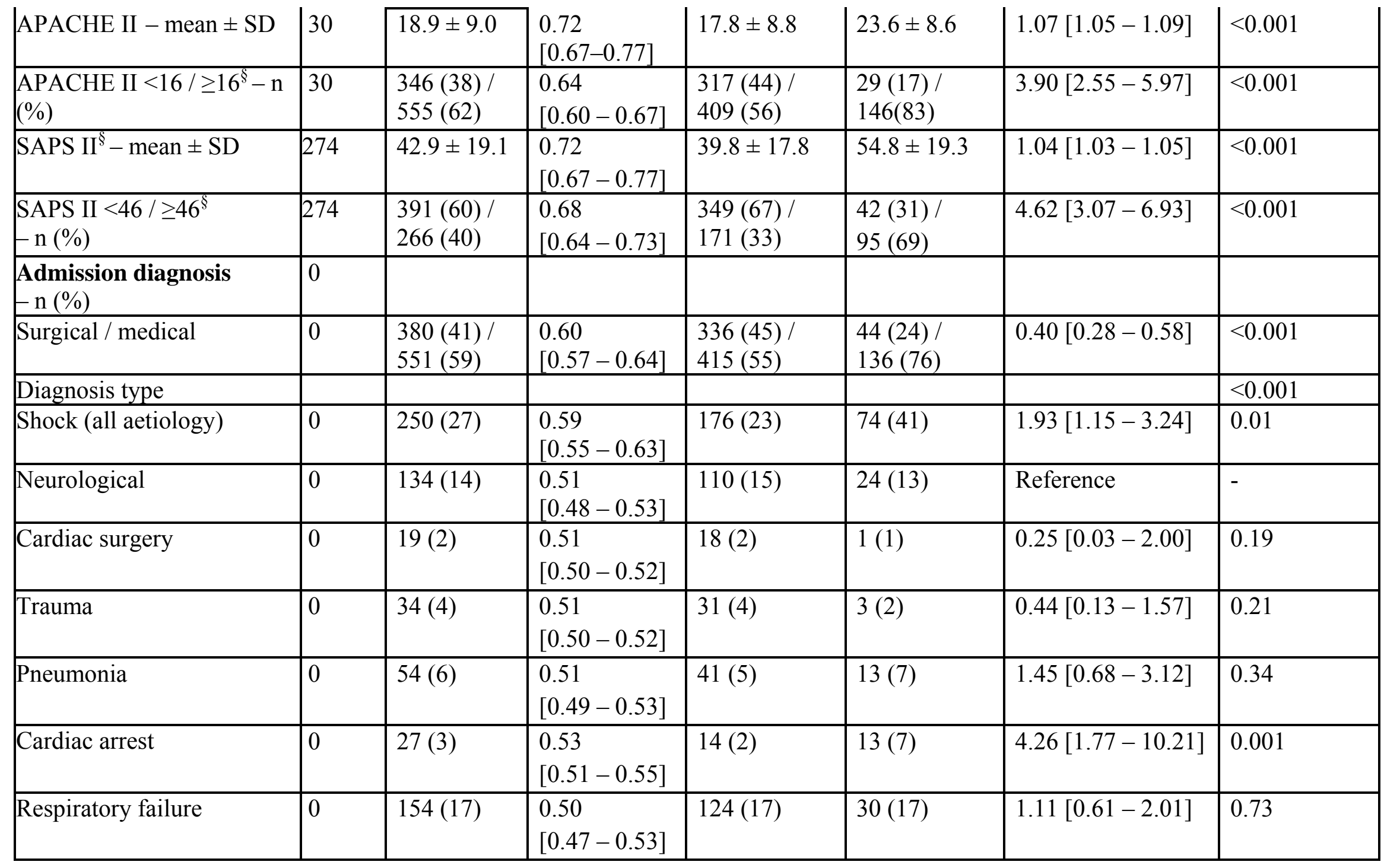




\begin{tabular}{|l|l|l|l|l|l|l|l|}
\cline { 3 - 7 } & & $9(1)$ & $\begin{array}{l}0.50 \\
{[0.49-0.50]}\end{array}$ & $8(1)$ & $1(1)$ & $0.57[0.07-4.80]$ & 0.61 \\
\hline Acute pancreatitis & 0 & $20(2)$ & $\begin{array}{l}0.51 \\
{[0.50-0.52]}\end{array}$ & $19(3)$ & $1(1)$ & $0.24[0.03-1.89]$ & 0.18 \\
\hline Liver failure & 0 & $12(1)$ & $\begin{array}{l}0.51 \\
{[0.49-0.52]}\end{array}$ & $8(1)$ & $4(2)$ & $2.29[0.64-8.23]$ & 0.20 \\
\hline Other & 0 & $218(23)$ & $\begin{array}{l}0.59 \\
{[0.56-0.62]}\end{array}$ & $202(27)$ & $16(9)$ & $0.36[0.19-0.71]$ & 0.003 \\
\hline
\end{tabular}

5 APACHE, Acute Physiology and Chronic Health Evaluation; BMI, body mass index; CI, confidence interval; OR, odds ratio; SAPS,

6 Simplified Acute Physiology Score; SD, standard deviations. 
Table 2 - Logistic regression multivariable analysis of factors associated with 28-

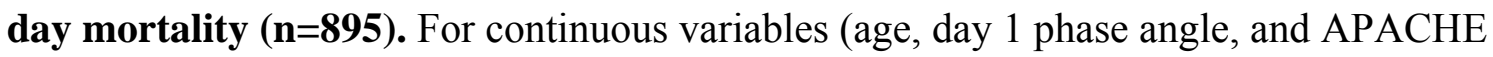
II), the adjusted odds ratio (aOR) are expressed for 1-point increase.

\begin{tabular}{|l|l|l|l|}
\hline Variables & aOR & 95\% confidence interval & $P$-value \\
\hline Age & 1.014 & $1.0016-1.0271$ & 0.03 \\
Day 1 phase angle & 0.86 & $0.78-0.96$ & 0.008 \\
$\begin{array}{l}\text { APACHE II } \\
\text { Admission diagnosis : } \\
\text { surgery vs. Medicine } \\
\text { Other diagnosis }\end{array}$ & 1.08 & $1.06-1.11$ & $<0.001$ \\
& 0.51 & $0.33-0.79$ & 0.002 \\
\hline
\end{tabular}

APACHE, Acute Physiology and Chronic Health Evaluation. 


\section{Figures legends}

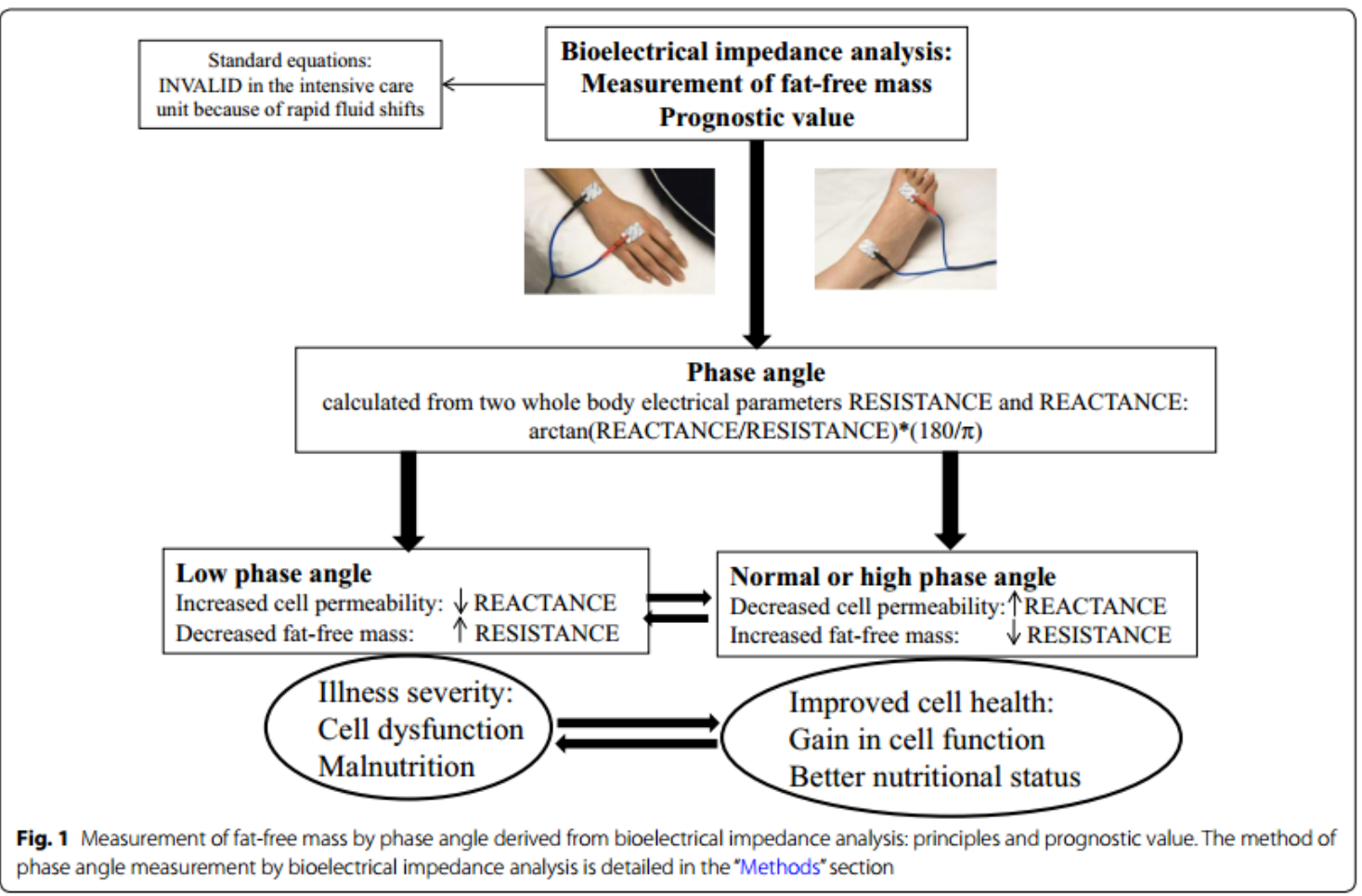

Figure 1 - Measurement of fat-free mass by phase angle derived from bioelectrical

impedance analysis: principles and prognostic value. The method of phase angle

measurement by bioelectrical impedance analysis is detailed in the dedicated paragraph

of the 'methods' section. 


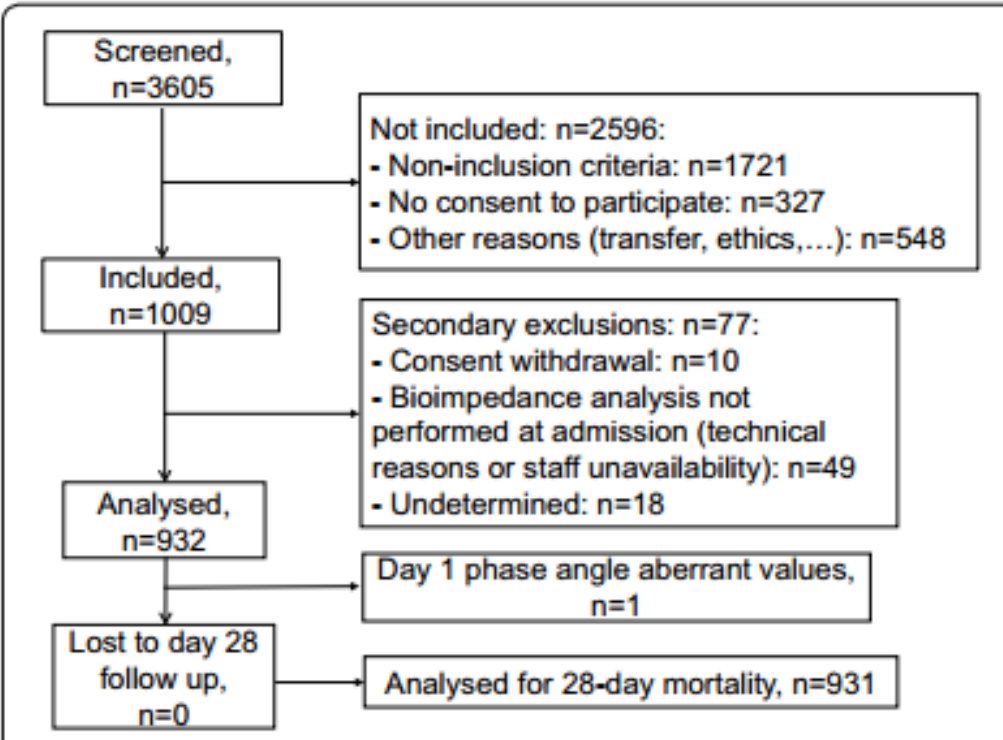

Fig. 2 Study flow chart

Figure 2 - Study flow chart.

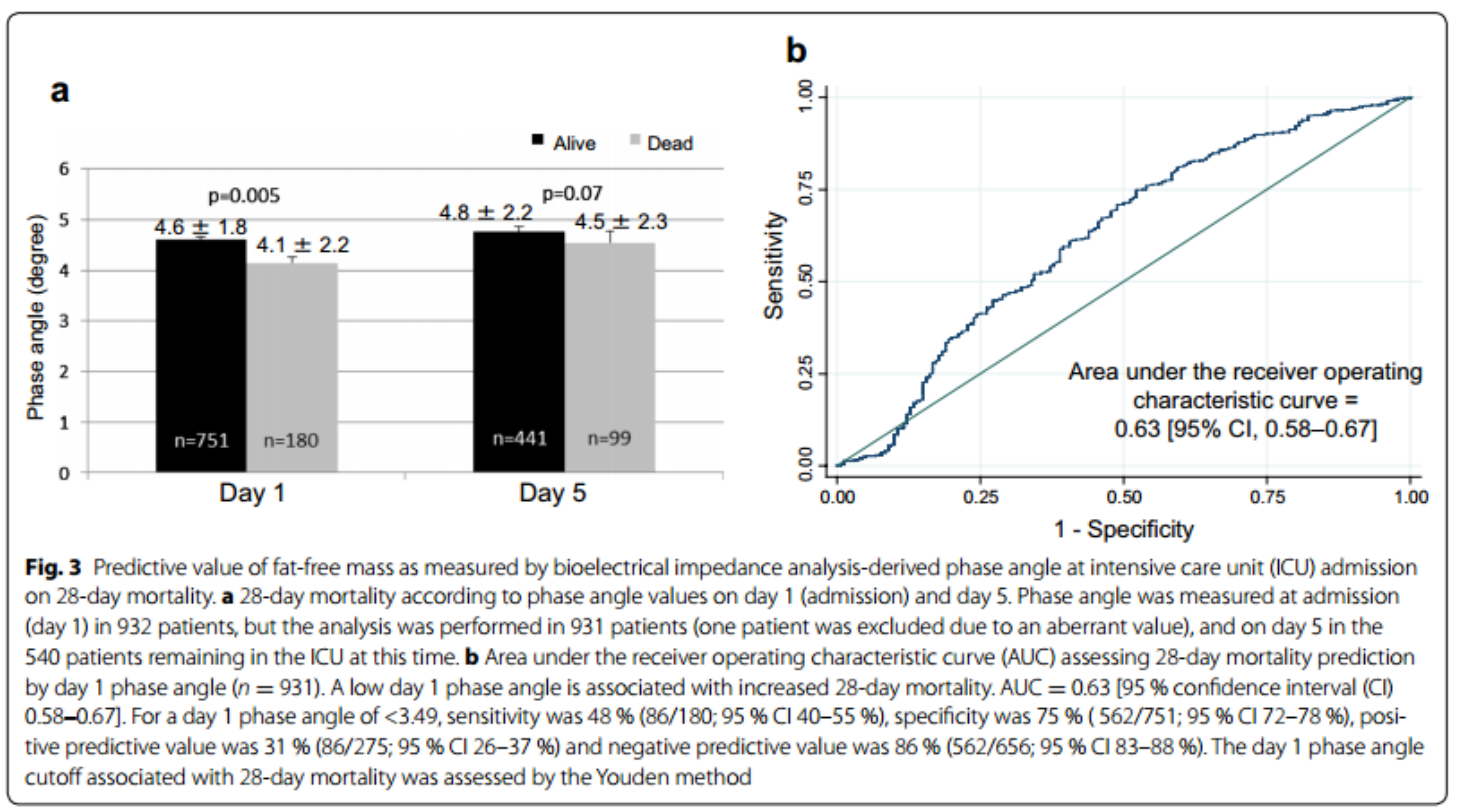

Figure 3 - Predictive value of fat-free mass, measured by bioelectrical impedance

analysis-derived phase angle at intensive care unit admission, on 28-day mortality.

(A) 28-day mortality according to phase angle values at day 1 and day 5. Phase angle 
was measured at admission (day 1) in 932 patients, but the analysis was performed in 931 patients (one patient was excluded because of an aberrant value), and at day 5 in the 540 patients still in the intensive care unit at this time. (B) Area under the receiver operating characteristic curve (AUC) assessing day-28 mortality prediction by day 1 phase angle (n=931). A low day 1 phase angle is associated with increased 28-day mortality. AUC $=0.63$ [95\% confidence interval, 0.58-0.67]. For a day 1 phase angle $<3.49$, sensitivity, specificity, positive and negative predictive values were respectively: $48 \%, 86 / 180$, [95\% confidence interval, 40-55], 75\%, 562/751, [72-78], 31\%, $86 / 275$, [26-37], and $86 \%, 562 / 656$, [83-88]. The day 1 phase angle cut-off associated with 28-day mortality was assessed by the Youden method. 


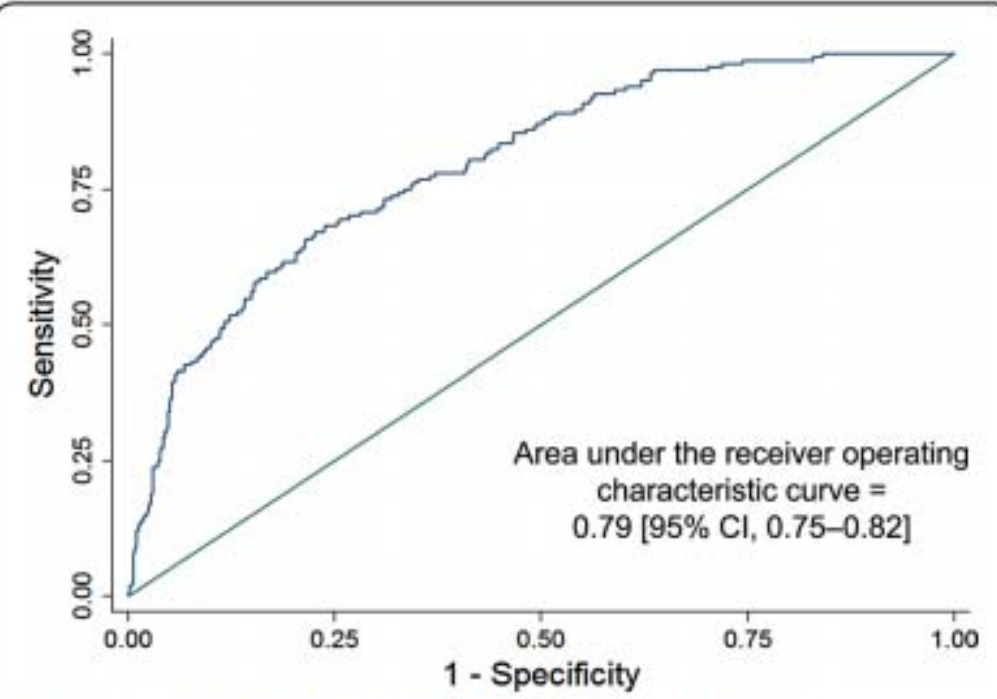

Fig. 4 Predictive value of the multivariable composite score for 28-day mortality ( $n=895)$. The score was determined by multivariable logistic regression and calculated as: risk-score $=-3.55(95 \%$ $\mathrm{Cl}-4.67$ to -2.43$)-0.67(95 \% \mathrm{Cl}-1.11$ to -0.24$)$ (if surgical admission diagnosis) +0.014 (95\% Cl 0.002-0.027) $\times$ age -0.146 ( $95 \% \mathrm{Cl}-0.254$ to -0.039$) \times$ day 1 phase angle $+0.0784 \times$ APACHE II -0.94 ( $95 \% \mathrm{Cl} 0.054-0.102$ ) (if admission diagnosis is other than one of those listed). AUC $=0.79$ ( $95 \% \mathrm{Cl} 0.75-0.82$ ). For a risk-score of $\geq 0.1716$, sensitivity was $77 \%(132 / 172 ; 95 \% \mathrm{Cl} 70-83 \%)$, specificity was $66 \%(477 / 723 ; 95 \% \mathrm{Cl} 62-69 \%)$, positive predictive value was $35 \%(132 / 378 ; 95 \% \mathrm{Cl} 30-40 \%)$ and negative predictive value was $92 \%(477 / 517 ; 95 \% \mathrm{Cl} 90-94 \%)$

Figure 4 - Predictive value of the multivariable composite score for 28-day

mortality $(\mathbf{n}=\mathbf{8 9 5})$. The score was determined by multivariable logistic regression and calculated as: risk-score $=-3.55[95 \%$ confidence interval, $-4.67 ;-2.43]-0.67[-1.11$; $-0.24]$ (if surgical admission diagnosis) $+0.014[0.002 ; 0.027]^{*}$ age $-0.146[-0.254$; $-0.039] *$ day 1 phase angle $+0.0784 *$ APACHE II $-0.94[0.054 ; 0.102]$ (if admission diagnosis is another one of those listed)]. Area under the receiver operating characteristic curve $=0.79[95 \%$ confidence interval, $0.75-0.82]$. For a score $\geq 0.1716$, sensitivity, specificity, positive and negative predictive values were respectively: 77\%, 132/172, 
[95\% confidence interval, 70-83]; 66\%, 477/723, [62-69]; 35\%, 132/378, [30-40]; and $92 \%, 477 / 517,[90-94]$. 